\title{
dspace.vutbr.cz
}

\section{Frequency Corrector Using Voltage Differencing Current Conveyor Transconductance Amplifiers}

\author{
ŠOTNER, R.; PETRŽELA, J.; JEŘÁBEK, J.; LANGHAMMER, L.
}

Proceedings of the 26th IEEE International Conference on Electronics Circuits and Systems, pp. 286-289

elSBN: 978-1-7281-0996-1

DOl: https://doi.org/10.1109/ICECS46596.2019.8964636

Accepted manuscript

(C2019 IEEE. Personal use of this material is permitted. Permission from IEEE must be obtained for all other uses, in any current or future media, including reprinting/republishing this material for advertising or promotional purposes, creating new collective works, for resale or redistribution to servers or lists, or reuse of any copyrighted component of this work in other works. ŠOTNER, R.; PETRŽELA, J.; JEŘÁBEK, J.; LANGHAMMER, L., "Frequency Corrector Using Voltage Differencing Current Conveyor Transconductance Amplifiers", Proceedings of the 26th IEEE International Conference on Electronics Circuits and Systems, pp. 286-289, 2019. DOI: 10.1109/10.1109/ICECS46596.2019.8964636. Final version is available at 


\title{
Fractional-Order Asymptotical Phase Shifter With Flat Magnitude Response
}

\author{
Roman Sotner*, Lukas Langhammer*, Jan Jerabek*, Tomas Dostal ${ }^{\dagger}$ \\ Email: \{sotner,jerabekj\}@feec.vutbr.cz langhammer@phd.feec.vutbr.cz tomas.dostal@vspj.cz \\ *SIX Research Center, Faculty of Electrical Engineering and Communication, Brno University of Technology, Brno, Czech Republic \\ ${ }^{\dagger}$ Department of Technical Studies, College of Polytechnics Jihlava, Jihlava, Czech Republic
}

\begin{abstract}
This work deals with design of fractional-order asymptotical phase shifter having constant magnitude response within almost three decades $(100 \mathrm{~Hz}-100 \mathrm{kHz})$ and frequency dependent phase difference going from 0 to -45 degrees. PSpice simulations employing macromodels of off-the-shelf active parts brought the results suitable for brief analysis of the complete solution of our phase shifter in both frequency and time domain. Magnitude flatness with only $\pm 0.3 \mathrm{~dB}$ variation and maximal phase error in the middle of operational bandwidth 3.7 degrees prove very good performance of designed circuit.
\end{abstract}

Keywords-All-pass filter, constant phase element, fractionalorder, phase shifter, variable gain amplifier

\section{INTRODUCTION}

Problem behind phase shift change in the integer-order (IO) circuits is twofold. First lies in achievable starting and ending value of a phase change of the asymptotical phase shifter (PS). Basic circuit theory [1] establishes that boundary values cannot be different than $\pm 90 \cdot n^{\circ}$ (degrees) when $n$ is natural number. Left and right phase shift limits are never exactly reached. Second drawback is fundamental phase shift of the asymptotical PS which is $90^{\circ}$ for circuit with minimal argument. Both drawbacks are general, not associated with particular circuit implementation or working regime and cannot be removed by any existing off-the-shelf circuitry.

Apart from PS with asymptotical phase change [1], [2], there are also PS-s where value of starting and ending phase shift is associated with some finite frequency range. In both cases there is a requirement for smooth phase change and tendency to keep constant magnitude frequency response over operational frequency range. In order to preserve overall circuit stability, poles need to be located in the open left halfplane of the complex space [3]. However, constant magnitude frequency response cannot be achieved simply by placing zeroes symmetrically to poles with respect to the vertical axis in the complex plane.

Majority of PS which are used in nowadays signal processing applications belongs to asymptotical class and these solutions are known as all-pass filters (APF) [3], [4]. These building blocks are designed most frequently as firstand second-order systems with decreasing maximal phase change of $180^{\circ}$ and $360^{\circ}$.

First-order voltage-mode structures of APF employing standard operational amplifiers are known for decades [3], [4]. Modern active elements and functional blocks [5], [6] have also been used in designs of many advanced concepts of APF circuits. APF employing single [7], [8] or few operational

This article is based upon work from COST Action CA15225, a network supported by COST (European Cooperation in Science and Technology). Research described in this paper was financed by the National Sustainability Program under grant LO1401 and by the Ministry of education, Youth and Sports under grant LTC18022 of Inter-Cost program. For the research, infrastructure of the SIX Center was used. transconductance amplifiers (OTAs) [9], [10] have been widely studied. In many publications APF were also implemented by using modern but still only hypothetical active elements [11]-[17]. Promising APF topologies with single differential voltage current conveyor [11], current differencing transconductance amplifier [16], current-mode APF with single [17] or few special types of current conveyors [12] could be also marked as widely used concepts.

Significant attention was also attracted to synthesis of the second-order APF sections. APF can sometimes be found as one possible frequency response of universal filter, see [19][24] and references therein. Several voltage-mode conceptions can be found in [18], [19]. The current-mode example is available for example in [20]. The hybrid mixedmode circuits were developed and reported in studies [21], (current and transimpedance mode), [22], [23] (transadmittance and transimpedance mode) and [24] (transimpedance mode).

Fractional-order elements and systems [25] seem to be very useful devices in PS design in order to generate arbitrary value of maximal (asymptotical) value of available phase shift. Unfortunately, topologies of first-order APF filters having standard transfer functions in form $\left.K(\mathrm{~s})=\left(\omega_{0}-\mathrm{s}\right) /\left(\omega_{0}+\mathrm{s}\right)\right)$ are not suitable for construction of fractional-order APS when integer-order capacitor is simply replaced by fractional-order capacitor, frequently referred to as constant phase element (CPE) [26], [27], [28]. The magnitude response of a such transfer is similar to band-reject filter, i.e. magnitude is not flat [29], [30] than it is expected for APF. Therefore, different approaches must be explored. This paper brings results of analyses how to solve above noted issue. The proposed methodology supposes simple design of fractional-order two-port (with asymptotically changing phase response) and method for automatic compensation of magnitude response that has certain slope $( \pm 20 \cdot \alpha \mathrm{dB} / \mathrm{dec}$; where $\alpha$ represents order of the fractional-order element) outside of the pass-band (without its compensation).

\section{Proposed Phase SHIFTER}

Figure 1 explains the idea of proposed system. The socalled acting path includes two-port having magnitude response that is subject of compensation and the variable gain amplifier controllable from so-called sensing path. The sensing path consists of three important blocks: a) two-port having exactly reciprocal frequency response to the two-port in acting path, b) peak envelope diode detector and c) summing amplifier that sets initial gain in "pass-band" of the two-port and simultaneously reacts on increasing "error" voltage from diode detector when magnitude of the two-port in sensing path increases (see Fig. 1). An analogical modification of error summing amplifier is required when reciprocal response of the two-port with decreasing magnitude 
is expected (not our case). The error signal is then subtracted from initial gain control voltage.

\section{A. Frequency Dependent Two-Ports}

The simplest solution of fractional-order PS can be obtained from R-CPE topology shown in Fig. 2(a). The transfer function of this elementary two-port has form:

$$
K_{F}(s)=\frac{\omega_{0}}{s^{\alpha}+\omega_{0}}=\frac{\frac{1}{R C_{\alpha}}}{s^{\alpha}+\frac{1}{R C_{\alpha}}} .
$$

Response of this two-port is similar to the standard integerorder R-C low-pass response. However, fractional-order case (C replaced by CPE) allows us to set maximal/asymptotical phase shift to $-\alpha \cdot 90^{\circ}$ whereas magnitude slope decreases with $-20 \cdot \alpha \mathrm{dB} / \mathrm{dec}$. The transfer function (1) can be expressed as magnitude and phase response in depence on frequency by help of Euler formula for complex calculus $\left(s^{\alpha}=\right.$ $\left.\omega^{\alpha}[\cos (\alpha \pi / 2)+j \cdot \sin (\alpha \pi / 2)]\right)$ as:

$$
\begin{gathered}
\left|K_{F}(j \omega)\right|=\frac{\omega_{0} \sqrt{\left[\omega^{\alpha} \cos \left(\alpha \frac{\pi}{2}\right)+\omega_{0}\right]^{2}+\left[\omega^{\alpha} \sin \left(\alpha \frac{\pi}{2}\right)\right]^{2}}}{\left[\omega^{\alpha} \cos \left(\alpha \frac{\pi}{2}\right)+\omega_{0}\right]^{2}+\left[\omega^{\alpha} \sin \left(\alpha \frac{\pi}{2}\right)\right]^{2}}, \\
\varphi(\omega)=\tan ^{-1}\left[\frac{-\omega^{\alpha} \sin \left(\alpha \frac{\pi}{2}\right)}{\omega^{\alpha} \cos \left(\alpha \frac{\pi}{2}\right)+\omega_{0}}\right] .
\end{gathered}
$$

The reciprocal (inverted) transfer function can be expressed as $K_{\mathrm{R}}(\mathrm{s})=1 / K_{\mathrm{F}}(\mathrm{s})$. The suitable circuit solution of such two-port, containing two OTAs [3], [5] and also additional controllable gain of overall transfer, can be represented by circuit shown in Fig. 2(b). Its transfer can be expressed as follows:

$$
K_{R}(s)=K_{0}\left(s^{\alpha}+\omega_{0}\right)=\frac{C_{\alpha}}{g_{m 1}}\left(s^{\alpha}+\frac{1}{C_{\alpha} R}\right),
$$

where $K_{0}=1 / \omega_{0}$ if $g_{\mathrm{m} 1}=1 / R$. Otherwise, active solution in Fig. 2(b) provides possibility to adjust gain of the transfer by transcoductance $g_{\mathrm{m} 1}$. This type of complex solution is used in order to allow processing of signals having lower level than diode envelope detector can detect.

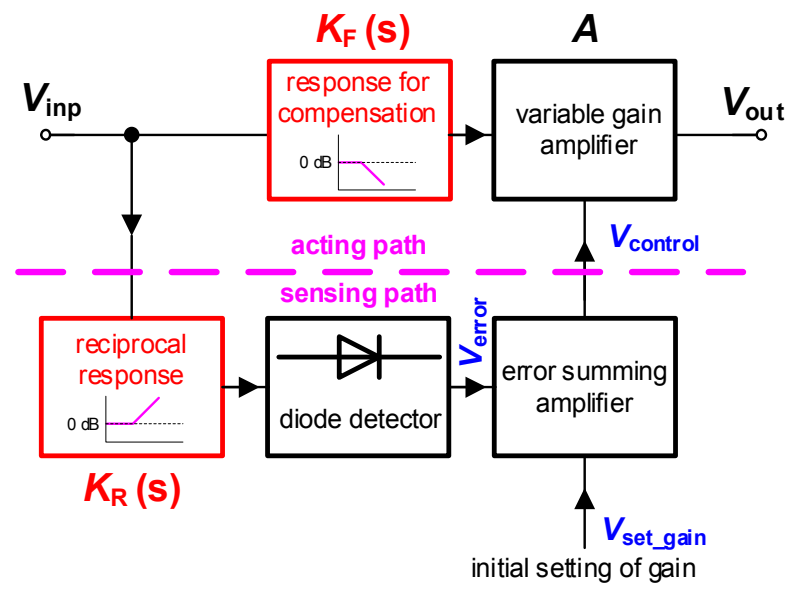

Fig. 1. The simplified block diagram of the proposed system.
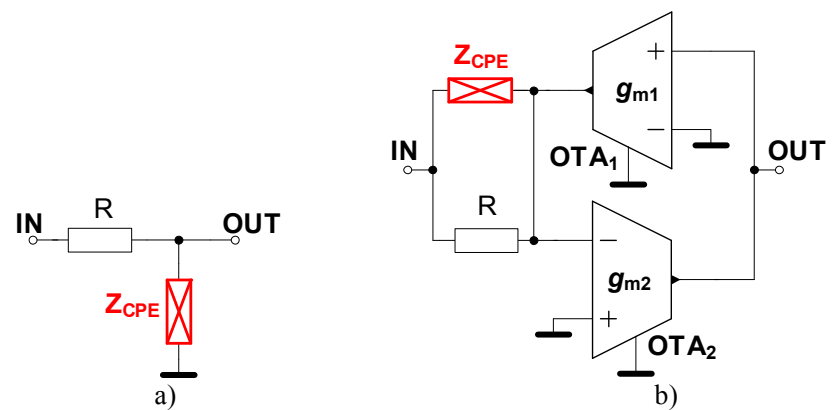

Fig. 2. Examples of the simplest two-ports: a) $K_{\mathrm{F}}(\mathrm{s})$ low-pass transfer in the main (acting) path, b) two-port having reciprocal response $K_{\mathrm{R}}(\mathrm{s})$ in sensing path with possibility to adjust the gain of the signal path.

\section{B. Phase Shifter Circuitry}

The circuitry of the fractional-order PS performing constant magnitude is given in Fig. 3. This scheme includes all necessary blocks from Fig. 1. Multiplier AD835 in acting path implements linearly controllable variable gain amplifier. The driving voltage $V_{\text {control }}$ should be limited below $1 \mathrm{~V}$ due to dynamical restriction of linearity. The feedback resistors $R_{\mathrm{f} 1,2}$ create small amplification (about 4.3) The overall gain of the variable gain amplifier can be found as $\pm A \cong \pm V_{\text {control }} \cdot\left(R_{\mathrm{f} 1}+R_{\mathrm{f} 2}\right) / R_{\mathrm{f} 2}$. The amplification can be easily inverted by polarity of $V_{\text {control }}$ or interchange of inputs $\left(y_{1} \leftrightarrow y_{2}\right)$. The summing stage employing standard voltage-mode operational amplifier OPA2650 generates voltage $V_{\text {control }}$ as a sum of static value $V_{\text {set gain }}$ (set to the middle of linear part of $\mathrm{DC}$ transfer response available for AD835-based variable gain amplifier) and dynamically variable component achieved after peak envelope detector. The time constant of the detector must be set optimally for expected operational band. Operation of the sensing branch is very simple. The pass-band of the $K_{\mathrm{R}}(\mathrm{s})$ response is not influencing static gain of the variable gain amplifier. The detector creates constant voltage contribution to the $V_{\text {set gain. }}$. However, the DC error voltage from detector starts to increase when magnitude response of $K_{\mathrm{F}}(\mathrm{s})$ decreases (reciprocal transfer $K_{\mathrm{R}}(\mathrm{s})$ in sensing path provides increasing output level in dependence of slope of magnitude trace and frequency of input signal). This relation can be approximately expressed as: $A \sim V_{\text {set_gain }}+V_{\text {inp }}(f)$. The full transfer function of the proposed system can be approximately expressed as:

$$
K_{P S}(s) \cong K_{F}(s) A\left(V_{\text {inp }}(f)\right) .
$$

OTAs employed in $K_{\mathrm{R}}(\mathrm{s})$ block are implemented by OPA860. All used active elements are supplied by $\pm 5 \mathrm{~V}$.

\section{SimULATIONS}

Our design supposes operational bandwidth from $100 \mathrm{~Hz}$ up to $100 \mathrm{kHz}$. All particular values of active and passive parameters are already indicated in Fig. 3. Whole circuitry was simulated in the PSpice (OrCAD 16.6) simulation software. The selected transfers of $K_{\mathrm{F}}(\mathrm{s})$ and $K_{\mathrm{R}}(\mathrm{s})$ are represented by two-ports symbolically described by equations (1) and (4) respectively.

Particular circuit solution approximating the CPE impedance of capacitive character is shown in Fig. 4 . The values of RC elements (Table I) were calculated by method proposed by Valsa et al. [26], [27] for $\alpha=1 / 2\left(\varphi_{\alpha}=45^{\circ}\right)$, with theoretical phase ripple $\Delta \varphi_{\alpha}=0.2^{\circ}$ and validity in bandwidth from $1 \mathrm{~Hz}$ up to $100 \mathrm{MHz}$ in ideal case. 
The frequency responses of proposed phase shifter are shown in Fig. 5. Magnitude responses of $K_{\mathrm{F}}(\mathrm{s}), K_{\mathrm{R}}(\mathrm{s})$ and $K_{\mathrm{PS}}$ indicates intentions of the design. The output response of the phase shifter (Fig. 3) has flat gain set approximately to $-8.4 \mathrm{~dB}$ with very small observed fluctuation $\pm 0.3 \mathrm{~dB}$ (red trace in Fig. 5(a)). The output phase response (red crosses in Fig. 5(b)) follows the phase response of $K_{\mathrm{F}}(\mathrm{s})$ transfer block. The black trace was obtained from AC simulations, the red points in time consuming transient analyses. Note that simple change of driving input of variable gain amplifier $\left(\mathrm{y}_{1} \leftrightarrow \mathrm{y}_{2}\right)$ allows inversion $\left(180^{\circ}\right)$ of this response. The increasing error of phase at low frequencies $\left(+5^{\circ}\right.$ at $\left.100 \mathrm{~Hz}\right)$ is given by capacitive coupling (DC offset cancellation for measuring function in PSpice) of the output (not shown in Fig. 3). The maximal deviation of theory $\left(K_{\mathrm{F}}(\mathrm{s})\right)$ and simulated output response of phase shifter in the expected operational band $(\geq 200 \mathrm{~Hz}$ and $<100 \mathrm{kHz}$ ) where AC coupling has no effect was found at $5 \mathrm{kHz}$ and yields $-3.7^{\circ}$.

Figure 6 illustrates several examples of output transient responses for selected frequencies $(1,10,100 \mathrm{kHz})$ and input level $500 \mathrm{mV}_{\mathrm{p} \text {-p. }}$ Of course, threshold voltage of diode $\mathrm{D}$ has to be overcomed in order to operate properly. Reaction of the sensing path ( $\left.V_{\text {control }}\right)$ on frequency (observed in operational band) of the input signal of the PS is given in Fig. 7.

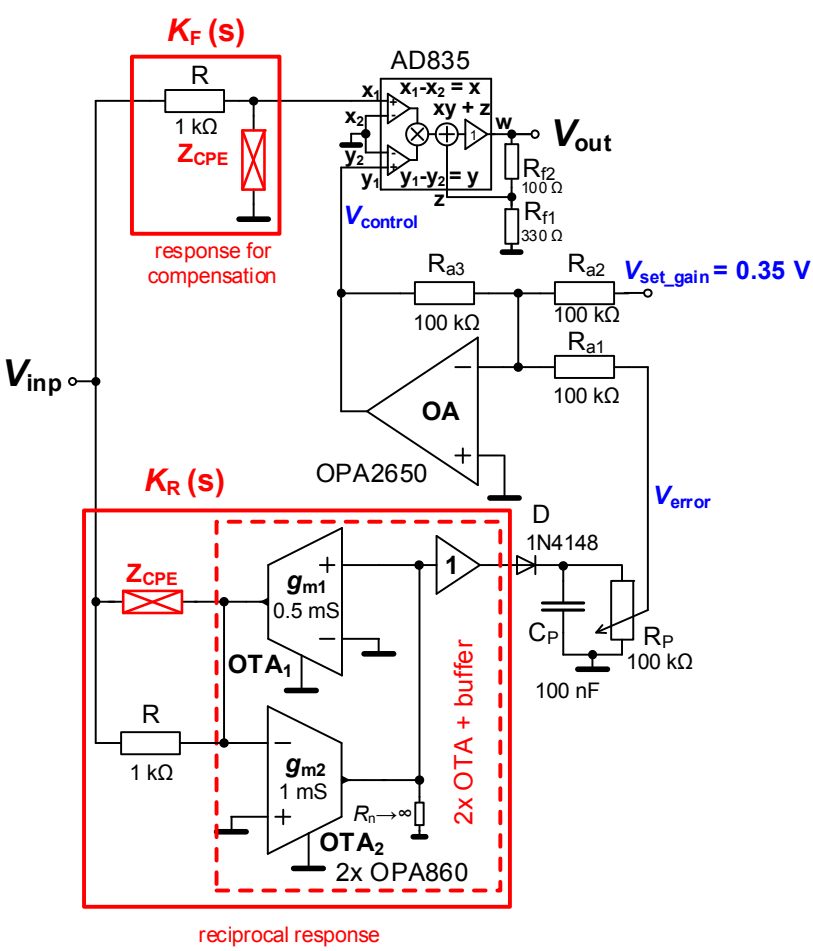

Fig. 3. Full circuitry of the proposed fractional-oder phase shifter.

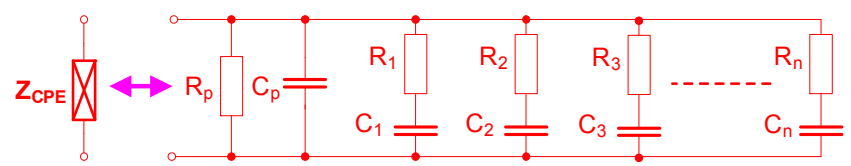

Fig. 4. CPE RC network used in tested two-ports.
TABLE I. PARAMETERS OF CPE

\begin{tabular}{|c|c|c|c|c|c|c|}
\hline$i$ & 1 & 2 & 3 & 4 & 5 & 6 \\
\hline$\overline{C_{\mathrm{i}}}$ & $4.35 \mu \mathrm{F}$ & $1.95 \mu \mathrm{F}$ & $870 \mathrm{nF}$ & $389 \mathrm{nF}$ & $174 \mathrm{nF}$ & $78 \mathrm{nF}$ \\
\hline$R_{\mathrm{i}}$ & $230 \mathrm{k} \Omega$ & $103 \mathrm{k} \Omega$ & $46 \mathrm{k} \Omega$ & $20.6 \mathrm{k} \Omega$ & $9.2 \mathrm{k} \Omega$ & $4.1 \mathrm{k} \Omega$ \\
\hline$i$ & 7 & 8 & 9 & 10 & 11 & 12 \\
\hline$C_{\mathrm{i}}$ & $35 \mathrm{nF}$ & $16 \mathrm{nF}$ & $7 \mathrm{nF}$ & $3.1 \mathrm{nF}$ & $1.4 \mathrm{nF}$ & $623 \mathrm{pF}$ \\
\hline$R_{\mathrm{i}}$ & $1.8 \mathrm{k} \Omega$ & $822 \Omega$ & $368 \Omega$ & $164 \Omega$ & $74 \Omega$ & $33 \Omega$ \\
\hline$i$ & 13 & 14 & \multirow{3}{*}{\multicolumn{4}{|c|}{$\begin{array}{l}C_{\mathrm{p}}=100 \mathrm{pF} \\
R_{\mathrm{p}}=280 \mathrm{k} \Omega\end{array}$}} \\
\hline$C C_{\mathrm{i}}$ & $280 \mathrm{pF}$ & $125 \mathrm{pF}$ & & & & \\
\hline$R_{\mathrm{i}}$ & $15 \Omega$ & $7 \Omega$ & & & & \\
\hline
\end{tabular}

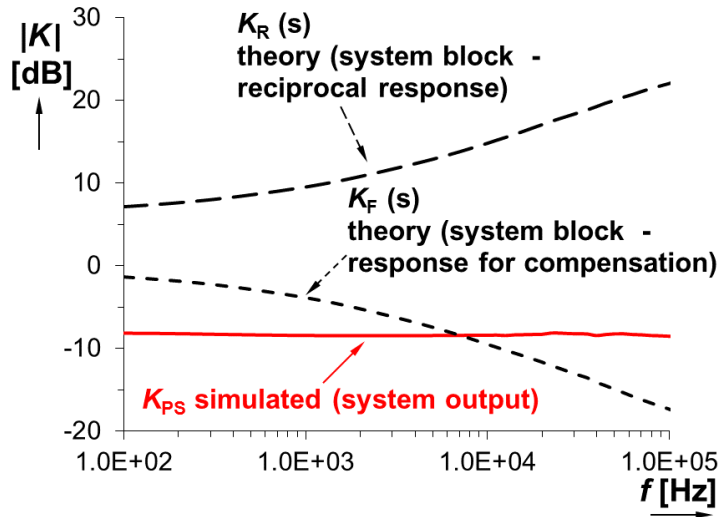

a)

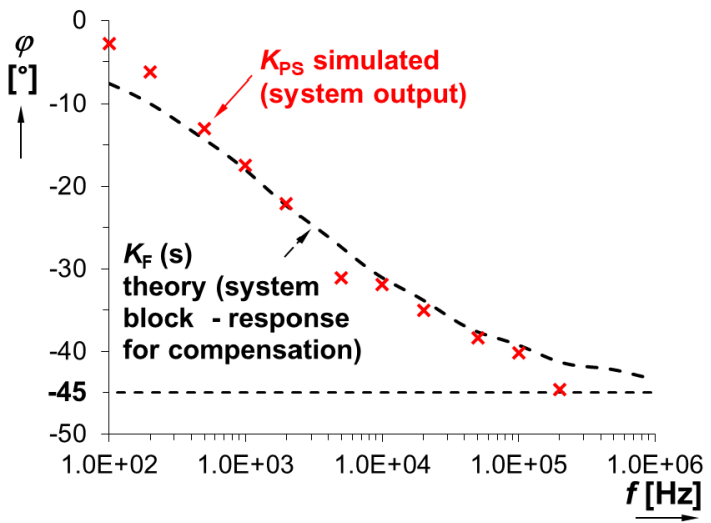

b)

Fig. 5. Frequency responses of proposed phase shifter, a) magnitude responses including transfer-ports $K_{\mathrm{F}}(\mathrm{s})$ and $K_{\mathrm{R}}(\mathrm{s})$, b) phase responses (compared with two port $K_{\mathrm{F}}(\mathrm{s})$ ).

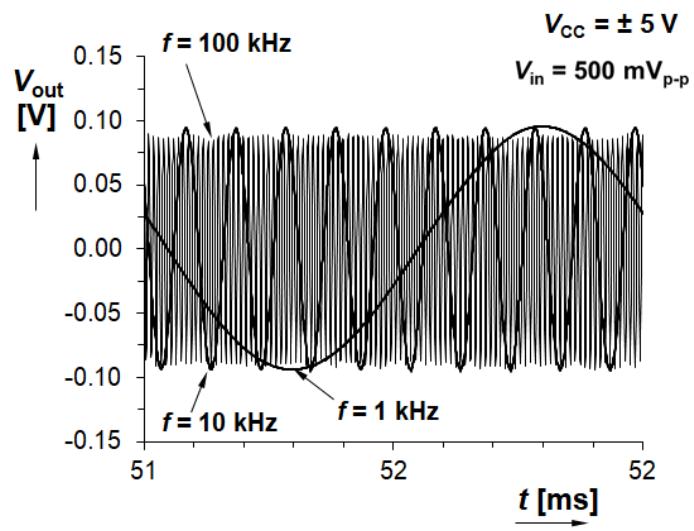

Fig. 6. Transient responses of the output signals for different input frequencies of the operational bandwidth processed by phase shifter. 


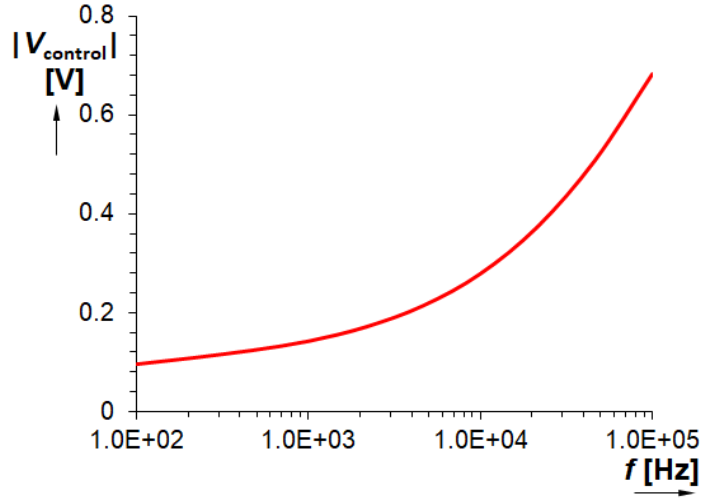

Fig. 7. Dependence of driving voltage $V_{\text {control }}$ on frequency (operational bandwidth) of the input signal $\left(500 \mathrm{mV}_{\mathrm{p}-\mathrm{p}}\right)$ of the phase shifter.

\section{CONCLUSION}

The peak envelope diode detector represents the main source of latency in reaction on changes due to its inertial character. There is not so significant delay required for loop auto-stabilization as in automatically controllable amplifiers. Simulations confirmed usability of the system for operational bandwidth from $100 \mathrm{~Hz}$ up to $100 \mathrm{kHz}$ with magnitude ripple $\pm 0.3 \mathrm{~dB}$ and maximal phase deviation in the middle of the operational bandwidth equal to $-3.7^{\circ}$. The results indicate that proposed concept is useful for obtainment of flat magnitude response and, moreover, arbitrary settable maximal phase shift (by variable order of the $Z_{\mathrm{CPE}}$ element).

\section{REFERENCES}

[1] J. Petrzela, "Arbitrary phase shifters with decreasing phase", In Proceedings of the $37^{\text {th }}$ International Conference on Telecommunications and Signal Processing (TSP), 2014, pp. 329-333.

[2] J. Petrzela, "Arbitrary phase shifters with increasing phase", In Proceedings of the $38^{\text {th }}$ International Conference on Telecommunications and Signal Processing (TSP), 2015, pp. 319-324.

[3] W. Chen, The Circuits and Filters Handbook. Boca Raton, FL: CRC Press, 2002.

[4] R. Raut, M. N. S. Swamy, Modern Analog Filter Analysis and Design: A practical approach. Weinheim, Germany: Willey-VCH Verlag GmbH and Co. KGaA, 2010.

[5] D. Biolek, R. Senani, V. Biolkova, Z. Kolka, "Active elements for analog signal processing: Classification, Review and New Proposals", Radioengineering, vol. 17, no. 4, pp. 15-32, 2008.

[6] R. Senani, D. R. Bhaskar, and A. K. Singh, Current Conveyors: Variants, Applications and Hardware Implementations. Springer International Publishing, Switzerland, 2015.

[7] B. Metin, K. Pal, S. Minaei, O. Cicekoglu, "Trade-offs in the OTAbased analog filter design", Analog Integrated Circuits and Signal Processing, vol. 60, no. 3, pp. 205-213, 2009.

[8] N. A. Shah, S. N. Ahmad, "Electronically tunable OTA-based all-pass circuit", International Journal of Electronics, vol. 68, no. 6, 963-966, 1990.

[9] D. V. Kamat, P. V. Ananda Mohan, K. Gopalakrishna Prabhu, „Novel first-order and second-order current-mode filters using multiple-output operational transconductance amplifiers“, Circuits, Systems and Signal Processing, vol. 29, no. 3, 553-576, 2010.

[10] P. Promee, K. Angkeaw, J. Chanwutitum, K. Dejhan, "Dual input allpass networks using MO-OTA and its application", In Proceedings of the Int. Conference on Electrical Engineering/Electronics, Computer,
Telecommunications and Information Technology (ECTI-CON), 2007, pp. 129-132.

[11] J.W. Horng," DVCCs based high input impedance voltage-mode firstorder allpass, highpass and lowpass filters employing grounded capacitor and resistor", Radioengineering, vol. 19, no. 4, pp. 653-656, 2010.

[12] R. Sotner, N. Herencsar, J. Jerabek, K. Vrba, T. Dostal, W. Jaikla, "Novel first-order all-pass filter applications of z-copy voltage differencing current conveyor", Indian Journal of Pure \& Applied Physics, vol. 53, no. 8, 537-545, 2015.

[13] W. Jaikla, A. Noppakarn, S. Lawanwisut, "New gain controllable resistor-less current-mode first order allpass filter and its application", Radioengineering, vol. 21, no. 1, 312-316, 2012.

[14] N. Herencsar, S. Minaei, J. Koton, E. Yuce, K. Vrba, "New resistorless and electronically tunable realization of dual-output vm all-pass filter using VDIBA", Analog Integrated Circuits and Signal Processing, vol. 22 , no. 1, 141-154, 2013.

[15] W. Tangsrirat, "On the realization of first-order current-mode AP/HP filter", Radioengineering, vol. 22, no. 4, 1007-1015, 2013.

[16] A. Lahiri, A. Chowdhury, "A novel first-order current-mode all-pass filter using CDTA", Radioengineering, vol. 18, no. 3, 300-305, 2009.

[17] M. Higashimura, Y. Fukui, "Realization of current-mode all-pass networks using a current conveyor", IEEE Transactions on Circuits and Systems, vol. 37, no. 5, 660-661, 1990.

[18] K. L. Pushkar, D. R. Bhaskar, D. Prasad, "Voltage-mode new universal biquad filter configuration using a single VDIBA", Circuits, Systems and Signal Processing, vol. 33, no. 1, 275-285, 2014.

[19] N. Takahashi, Y. Sumi, Y. Fukui, "Novel voltage-mode biquad without external passive elements", International Journal of Electronics, vol. 88 , no. 1, 13-22, 2001.

[20] J. W. Horng, "Current-mode and transimpedance-mode universal biquadratic filter using multiple outputs CCIIs", Indian Journal of Engineering and Materials Sciences, vol. 17, no. 3, 169-174, 2010.

[21] S. V. Singh, S. Maheshwari, D. Chauhan, "Single MO-CCCCTAbased electronically tunable current/trans-impedance-mode biquad universal filter", Circuits and Systems, vol. 2, no. 1, 1-6, 2011.

[22] H. P. Chen, "Tunable mixed-mode OTA-C universal filter", Analog Integrated Circuits and Signal Processing, vol. 58, no. 2 (2009), 135141, 2009.

[23] Ch. N. Lee, "Multiple-mode OTA-C universal biquad filters", Circuits, Systems and Signal Processing, vol. 29, no. 2, 263-274, 2010

[24] S. Kilinc, U. Cam, "Transimpedance type fully integrated biquadratic filters using operational transresistance amplifiers", Analog Integrated Circuits and Signal Processing, vol. 47, no. 2, 193-198, 2006.

[25] A. S. Elwakil, "Fractional-order circuits and systems: An emerging interdisciplinary research area", IEEE Circuits and Systems Magazine, vol. 10 , no. 4, pp. 40-50, 2010.

[26] J. Valsa, P. Dvorak, M. Friedl, "Network model of the CPE", Radioengineering, vol. 20, no. 3, pp. 619-626, 2011.

[27] J. Valsa, J. Vlach, "RC models of a constant phase element", International Journal of Circuit Theory and Applications, vol. 41, no. 1, pp. 59-67, 2013.

[28] J. Petrzela, R. Sotner, M. Guzan, "Implementation of constant phase elements using low-Q band-pass and band-reject filtering sections", In Proceedings of the 21st International Conference on Applied Electronics, 2016, pp. 205-209.

[29] N. Herencsar, A. Kartci, J. Koton, G. Tsirimokou, C. Psychalinos, "Voltage Gain-Controlled Third-Generation Current Conveyor and its All-Pass Filter Verification", In Proceedings of the $23^{\text {rd }}$ European Conference on Circuit Theory and Design (ECCTD), 2017, pp. 1-4.

[30] R. Sotner, N. Herencsar, J. Jerabek, J. Petrzela, T. Dostal, "Design of Integer/Fractional-Order Filter with Electronically Reconfigurable Transfer Response", In Proceedings of the $24^{\text {th }}$ IEEE International Conference on Electronics, Circuits and Systems (ICECS), 2017, pp. $156-159$. 